\title{
Characterisation of inorganic microparticles in pigment cells of human gut associated lymphoid tissue
}

J J Powell, C C Ainley, R S J Harvey, I M Mason, M D Kendall, E A Sankey, A P Dhillon, R P H Thompson
Gastrointestinal

Laboratory, The Rayne

Institute

J J Powell

C C Ainley

R S J Harvey

R P H Thompson

and Unit of Cell

Biology

I M Mason

M D Kendall

United Medical and

Dental Schools, St

Thomas' Hospital,

London SE1 7EH

Department of Histopathology, Royal

Free Hospital School of Medicine, London NW3 2QG, England

E A Sankey

A P Dhillon

Correspondence to:

Dr J J Powell,

Gastrointestinal Laboratory,

The Rayne Institute, St

Thomas' Hospital, London

SE1 7EH.

Accepted for publication

28 September 1995

\begin{abstract}
Macrophages at the base of human gut associated lymphoid tissue (GALT), become loaded early in life with dark granular pigment that is rich in aluminium, silicon, and titanium. The molecular characteristics, intracellular distribution, and source of this pigment is described. Laser scanning and electron microscopy showed that pigmented macrophages were often closely related to collagen fibres and plasma cells in GALT of both small and large intestine and contained numerous phagolysosomes, previously described as granules, that are rich in electron dense submicron sized particles. Morphological assessment, $x$ ray microanalysis, and image electron energy loss spectroscopy showed three distinct types of microparticle: type I - spheres of titanium dioxide, 100-200 nm diameter, characterised as the synthetic food-additive polymorph anatase; type II - aluminosilicates, $<100-400 \mathrm{~nm}$ in length, generally of flaky appearance, often with adsorbed surface iron, and mostly characteristic of the natural clay mineral kaolinite; and type III - mixed environmental silicates without aluminium, 100-700 $\mathrm{nm}$ in length and of variable morphology. Thus, this cellular pigment that is partly derived from food additives and partly from the environment is composed of inert inorganic microparticles and loaded into phagolysosomes of macrophages within the GALT of all human subjects. These observations suggest that the pathogenicity of this pigment should be further investigated since, in susceptible individuals, the same intracellular distribution of these three types of submicron particle causes chronic latent granulomatous inflammation.

(Gut 1996; 38: 390-395)
\end{abstract}

Keywords: Peyer's patch, gut associated lymphoid tissue, aluminium, silicon, titanium.

There are several reports on the elemental analysis of pigment that is present in the macrophages of gut associated lymphoid tissue (GALT), and aluminium, silicon, magnesium, titanium, and iron have been identified. ${ }^{1-3}$ In the most detailed study, Shepherd et $a^{2}$ showed aluminium, silicon, and titanium as granular pigment in macrophages located in the deep aspect of Peyer's patches in bowel from both normal subjects and patients with a variety of diseases. Furthermore, in resection specimens of bowel from patients with Crohn's disease, similar particles were seen around dilated lymphatics, in mesenteric lymph nodes, and in some transmural inflammatory aggregates. Shepherd et al concluded that the pigment is derived from the diet and actively taken up by Peyer's patches. There is no detailed information on the physicochemical structure of the pigment, which has been assumed to be inert undegradeable material of no significance. However, these same inorganic particulate elements can in other tissues cause inflammation and fibrosis, particularly in the lung.

GALT is responsible for the generation of immune responses to luminal antigens, and the macrophages play an important role by processing and degrading ingested material and presenting antigens from it to immunocompetent lymphocytes. When ingested microorganisms cannot be degraded by GALT macrophages, the resultant frustrated phagocytosis may yield a pathological response, as in ileocaecal tuberculosis. It is at least possible, therefore, that inorganic particles in the diet, which are taken up by GALT and resistant to degradation, could cause disease in susceptible individuals.

We have, therefore, used a combination of microanalytical techniques to carry out a physicochemical analysis to identify the precise composition and ultrastructural localisation of the pigment in human GALT.

\section{Methods}

Paraffin embedded histological slides prepared from surgically resected intestinal tissue from 20 patients were examined. The diagnoses were Crohn's disease $(n=10)$, ulcerative colitis $(n=5)$, and colonic carcinoma $(n=5)$. Fifteen specimens were from the distal ileum, three were ileocaecal, and two were from the colon. All contained lymphoid aggregates. Sections were taken from macroscopically normal areas of bowel and microscopically were normal or showed only mild inflammation.

Thick sections $(10 \mu \mathrm{m})$ were prepared and only lightly stained with haematoxylin and eosin to allow visualisation of pigment. Peyer's patches or large intestinal lymphoid aggregates were identified in the mucosa as domes of 


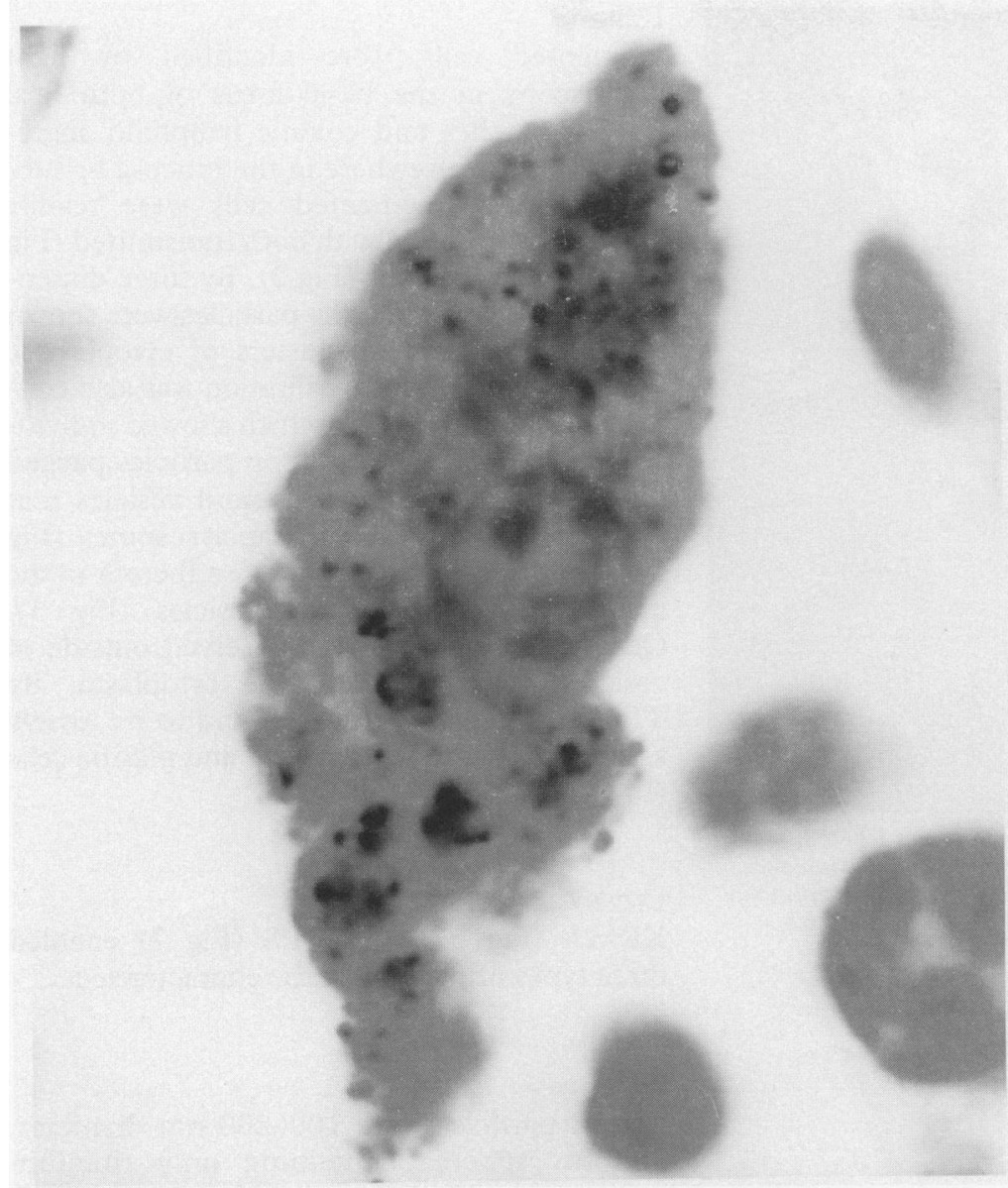

Figure 1: Typical pigmented cell, viewed in transmission mode, under the laser scanning microscope. The nucleus of the cell is evident and pigment abounds in the cytoplasm.
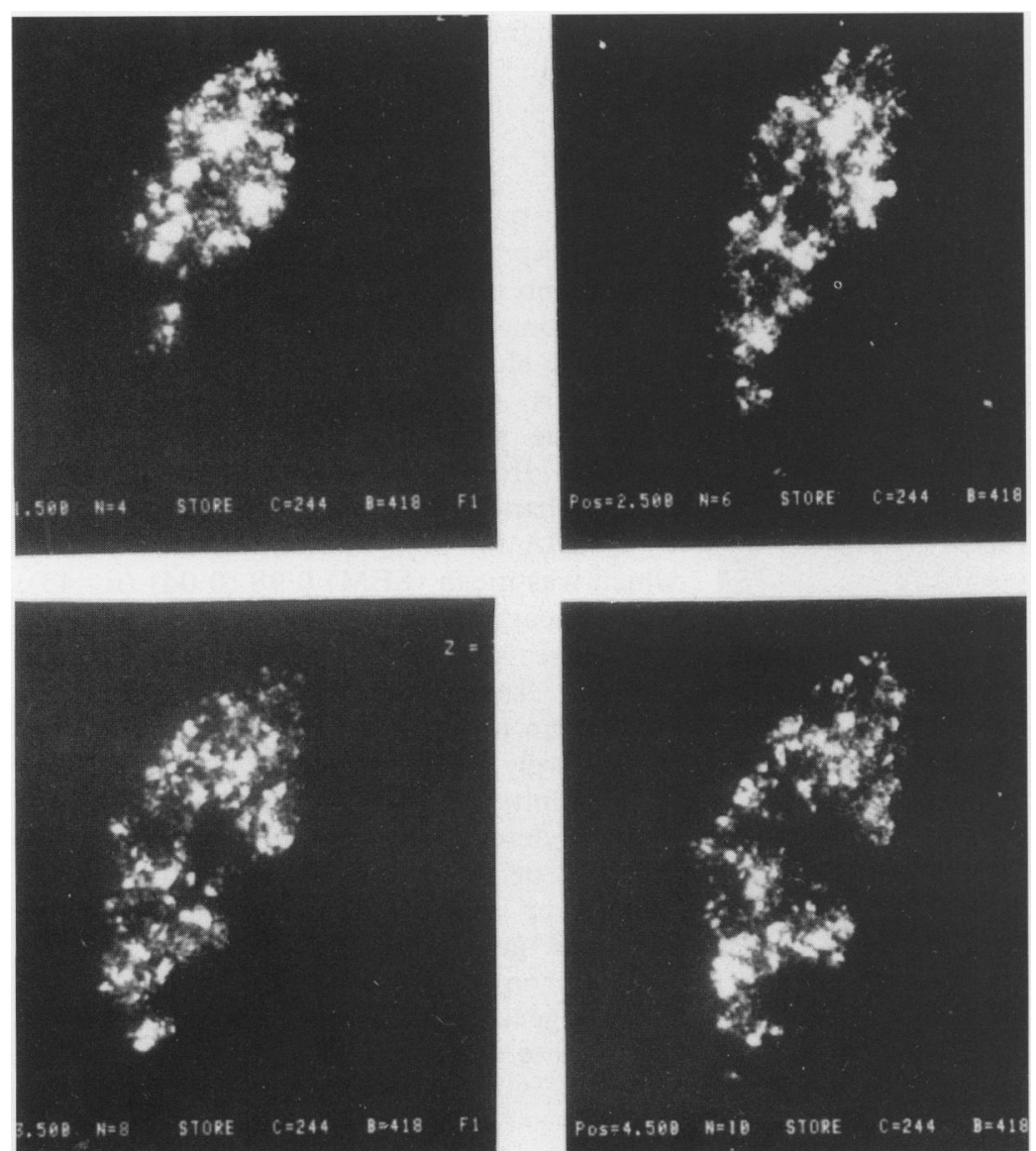

Figure 2: Same cell as in Figure 1, viewed in reflectance confocal mode under the laser scanning microscope. The cell is optically sectioned, at $1 \mu \mathrm{m}$ intervals, from top to bottom and four such sequential sections are shown. The microparticles, unlike the tissue, reflect the laser light and the non-reflecting area of the nucleus is evident. lymphoid tissue with a germinal centre lying beneath specialised flattened epithelium. The locations of any pigmented cells were recorded and the sections investigated by laser scanning microscopy (LSM; Carl-Zeiss Ltd, Welwyn Garden City, UK). Five pigmented cells were examined in sections from one patient with Crohn's disease, one with ulcerative colitis, and one with colonic carcinoma, and one cell in a section from each of the remaining 17 cases. The pigmented cells were initially identified under LSM with transmitted light using differential interference contrast optics, $\times 63$ immersion objective and $\times 40$ to 160 zoom, and an argon ion laser wavelength of $488 \mathrm{~nm}$. Images were obtained with reflected light LSM and using a helium neon wavelength of $633 \mathrm{~nm}$, confocal images of each cell were collected at $1 \mu \mathrm{m}$ intervals. The data were stored on computer and reconstructed in three dimensions.

Sections for transmission electron microscopy (TEM; Carl-Zeiss Ltd and Hitachi Scientific Instruments, Nissei-Sangyo Company Ltd, Reading, UK) were obtained by reprocessing appropriate areas of tissue from paraffin blocks of the above three cases. Small cores of tissue containing pigmented cells, which were removed from these blocks using a flattened renal biopsy needle, were embedded in standard TEM epoxy-resin (TAAB 812) and 200-500 $\mathrm{nm}$ sections were cut. Pigmented cells were viewed with TEM at magnifications between $\times 3000$ and 10000 . Individual particles for microanalysis were identified within vesicles in the cytoplasm of pigmented cells at magnifications of $\times 20000$ and above.

Individual particles were examined by $x$ ray microanalysis (XRMA; Link Analytical Instruments Microanalysis Group, High Wycombe, UK) in conjunction with TEM. This technique yields information on all elements with an atomic weight greater than that of sodium (atomic weight 22). Three pigmented cells were selected from each of the three patients, and 50 discrete particles were analysed per cell ensuring no overlap or interference from adjacent particles. Passing left to right across the pigmented cells with a duration of 100 seconds (live time) per particle, 20 analyses were carried out on particles less than $100 \mathrm{~nm}$ in length and 30 on those greater than $100 \mathrm{~nm}$. In some particles, where aluminium and silicon were co-localised, the ratios of these two elements were calculated by XRMA using a previously described method. ${ }^{4}$ Briefly, the ratio of peak heights of aluminium to silicon were compared to those from similar analyses of a series of standard aluminosilicate particles embedded in gelatin sections.

Imaging electron energy loss spectroscopy (EELS; Carl-Zeiss Ltd) was also performed to analyse those light elements of the particles below the range of XRMA and also to confirm the results for the major elements of interest measured by XRMA. Thus aluminium, carbon, chlorine, nitrogen, oxygen, phosphorus, silicon, sulphur, and titanium were all investigated. 


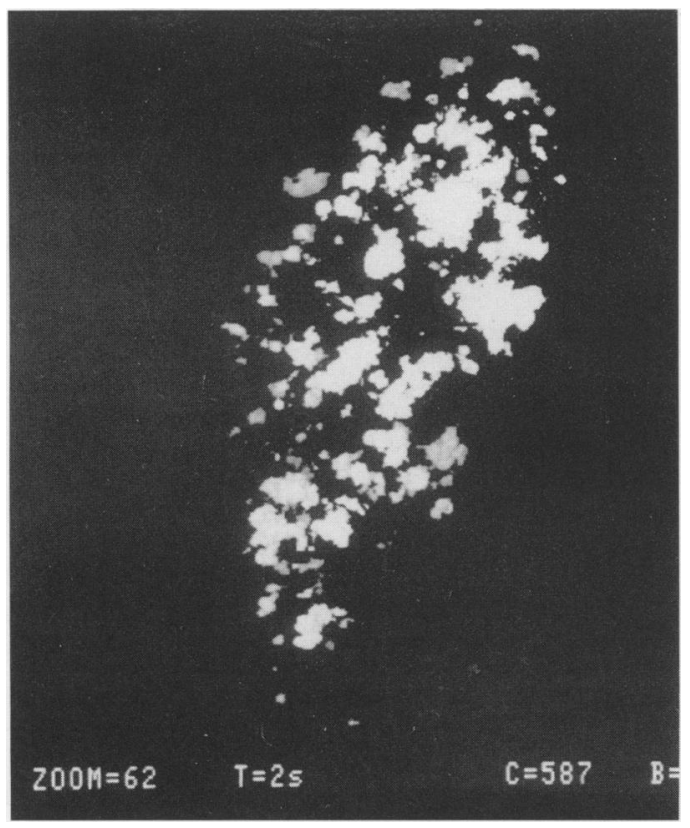

Figure 3: Image of the same cell in Figures 1 and 2, but reconstructed in pseudo three dimensions to illustrate the distinctly packaged areas of microparticles. Computational representation allows rotation of cells giving full three dimensional display.

\section{Results}

Pigmented cells were identified by light microscopy in the basal areas of both ileal Peyer's patches and colonic lymphoid aggregates, but not elsewhere in the mucosa or submucosa. The pigmented cells were readily identifiable by LSM with both transmitted (Fig 1) and reflected light (Fig 2). By three dimensional reconstruction, the particles were shown to be sequestered in clusters of cytoplasmic vesicles (Fig 3). This localisation was also confirmed by TEM (Fig 4), which showed individual electron-dense submicron particles packed mostly within membrane bound vesicles that had the appearances of phagolysosomes (Fig 5). These particles were largely adherent to the inside membrane of the vesicles (Fig 5). Occasional particles were observed outside of vesicles but still within the cytoplasm. By TEM, the cells were often found to be closely associated with collagen fibres and plasma cells (Fig 4).

TYPES OF PARTICLES

XRMA (Fig 6) and EELS (Fig 7) enabled three types of particles to be characterised.

Type I

Type I particles were $100-200 \mathrm{~nm}$ diameter, uniform spheres containing only titanium and oxygen. Titanium dioxide of this shape (Fig 5), size (Fig 5), and analytical purity (Figs 6 and 7) indicates a synthetic polymorph, namely anatase, which is food additive E171.

\section{Type II}

Type II particles were $<100-400 \mathrm{~nm}$ in length (Fig 5) containing aluminium, oxygen, and silicon often with some iron (Figs 6 and 7) and sometimes a group IA or IIA element. All those aluminosilicates without detectable group IA or IIA element were of flaky crystalline appearance. The first five such particles from each cell $(n=9)$ that were greater than $100 \mathrm{~nm}$ in length were examined by XRMA for their aluminium:silicon ratio, which was mean (SEM) $0.98(0.04)(n=45)$. The appearances and analyses of these particles were strongly suggestive of the clay mineral, kaolinite. The smaller particles ( $<100 \mathrm{~nm}$ in length) could only be analysed qualitatively, but were also of the appearance of kaolinite. Other aluminosilicates containing detectable elements of group IA (sodium or potassium) or group IIA (magnesium or calcium) were often also flaky, although generally more amorphous than kaolinite, and thus by appearance and analysis were suggestive of illite, mica, smectite or vermiculite.

\section{Type III}

Type III particles were 100-700 nm length, of variable morphology, and contained silicon and a number of elements including magnesium, 


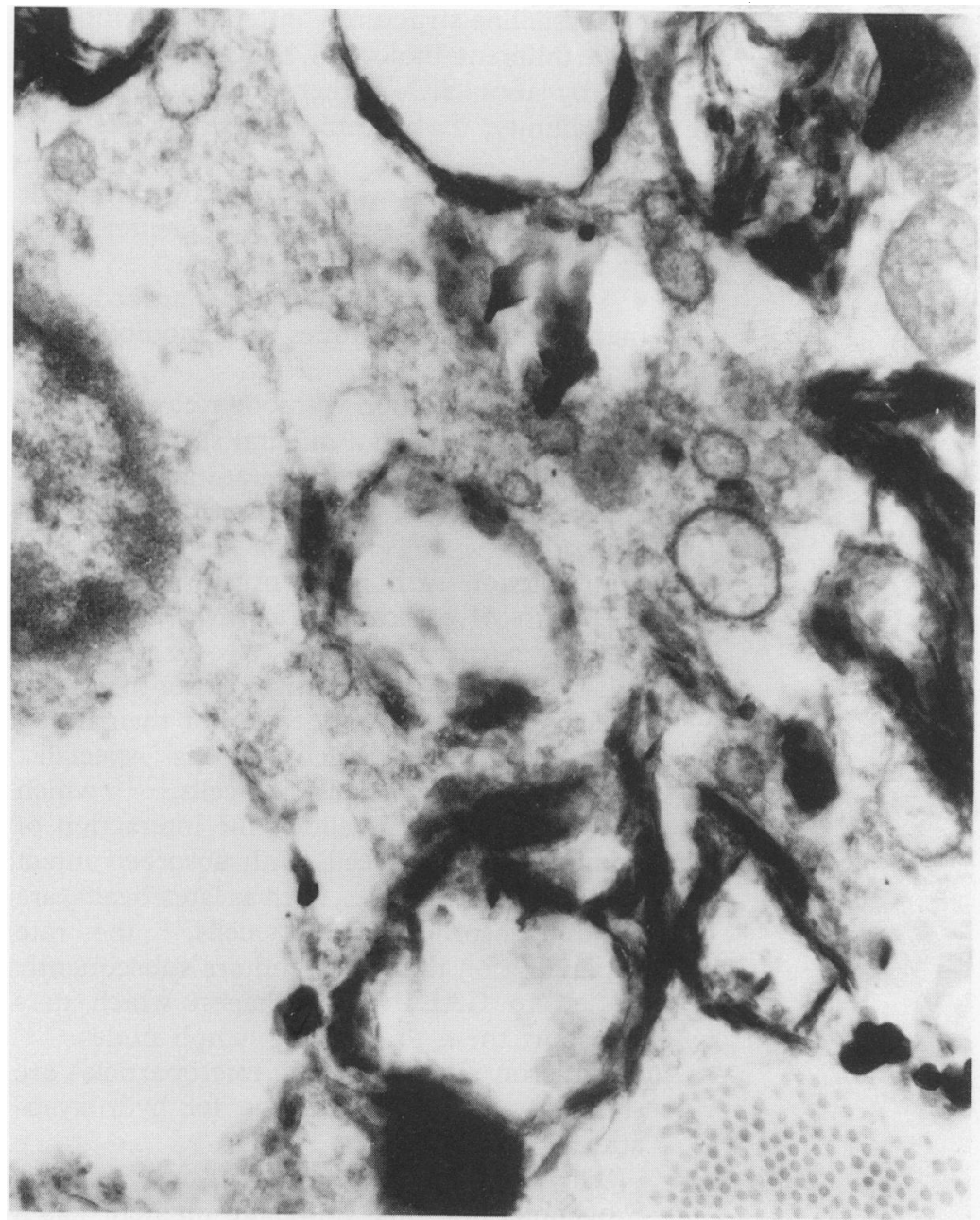

Figure 5: High power (original $\times 25000$ ) of pigment cell in Figure 4. Individual particles, largely within the vesicular areas, are better resolved for analysis.

potassium, sodium, and iron, but not aluminium. These were termed mixed silicates.

The analytical and size distribution of the particles is shown in Fig 8. There were no distinct differences in particle profiles between the patients according to diagnosis, or between Peyer's patches and large intestinal lymphoid aggregates.

\section{Discussion}

We have shown that the pigment cells in GALT contain specific inorganic particles, all of submicron size, and present largely within phagolysosomes. Shepherd et $a l^{2}$ first showed granular pigment in small intestine Peyer's patch macrophages that appeared micron sized and contained aluminium, silicon, and titanium. They did not carry out an ultrastructural analysis or study the molecular and physical structure of the pigment. However, we have now shown each granule to be, in fact, an intracellular phagolysosome, itself containing many submicron sized particles. Shepherd et al speculated that the pigment was derived from items in the diet, such as contaminants, food additives, or toothpaste, and they also showed that similar pigment was present in some draining lymph nodes, around dilated submucosal lymphatics, and, in one patient with Crohn's disease, in inflammatory aggregates. However, they did not find pigment in GALT elsewhere in the gastrointestinal tract, and this contrasts with our work where the few colonic lymphoid aggregates studied from the large intestine/ileo-caecal region also contained pigment without obvious qualitative or quantitative differences from that within the small intestinal Peyer's patches. Urbanski et al ${ }^{1}$ provided preliminary information on the subcellular structure of pigment cells and on the chemical composition of particles that remained on a filter after dissolution and filtering of intestinal tissue. They did not undertake detailed analyses of the particle types or their intracellular location, nor did they perform any in situ analyses, and hence also could only speculate on the source of the pigment which they attributed to atmospheric dust. With the techniques we have used, the molecular and physical structure of the pigment has been defined enabling us to identify three different types of particle and their sources.

The first is type I (titanium dioxide). Titanium dioxide is found as four distinct polymorphs, namely rutile, anatase, brookite, and $\mathrm{TiO} 2(\mathrm{~B})$. The last three are formed by weathering of $\mathrm{Ti}$ rich minerals and are common minor constituents of soils. Rutile is formed by metamorphism of the other polymorphs. All four polymorphs are white but are often impure and a red-brown colour is typical. Common impurities are $\mathrm{Fe}, \mathrm{Nb}, \mathrm{Ta}, \mathrm{V}, \mathrm{Cr}, \mathrm{Al}$, $\mathrm{Hf}$, and $\mathrm{Zr}^{5}$ Pure rutile and anatase are commercially synthesised, and their uses include: a white pigment base (mainly rutile) in paints, plastics, rubber and paper, a catalyst and catalyst support (anatase), and a food additive, E171 (anatase). High purity ( $>99 \%$ pure) is required for regular ingestion, and since this is easier to achieve with anatase than rutile, it is the former that is widely used in pharmaceuticals and food additives. It is uncertain when titanium dioxide was first introduced into the diet, but industrial production began in 1918 and usage has increased dramatically since 1945 in developed countries. ${ }^{6}$

We have shown anatase particles in GALT macrophages by XRMA and EELS; their consistent purity and polymorphic specificity strongly suggest that they are derived from the widely used food additive E171 rather than from environmental contamination. They may not be of great significance in view of the inert nature of titanium dioxide, ${ }^{78}$ which is not currently associated with human disease in any of its polymorphic forms. However, there is evidence that titanium dioxide may possess proinflammatory ${ }^{9}$ and membranolytic activity, ${ }^{10}$ while much recent work has focused on the marked ability of titanium dioxide to catalyse the generation of reactive oxygen species under specific conditions. ${ }^{11} 12$

Type II and III particle comprise aluminosilicates and silicates. Approximately $92 \%$ of the minerals in the earth's crust are silicates. The process of weathering generates soils in which the inorganic constituents are predominantly layer silicates (clays) and quartz. These ubiquitous dusts are therefore a constant contaminant of foods. Natural and synthetic silica and silicates have many uses, 


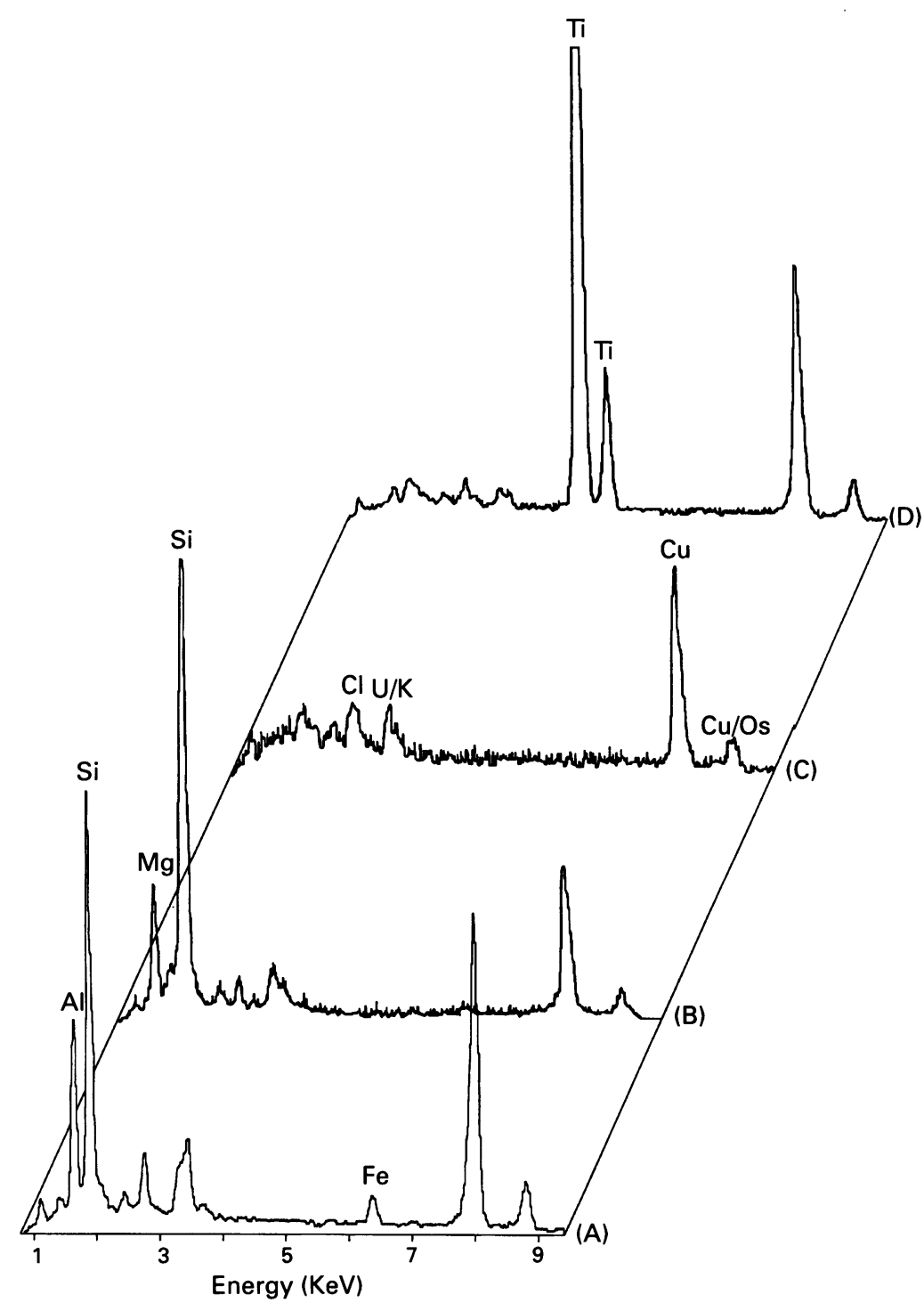

Figure 6: Typical $\mathrm{x}$ ray microanalysis spectra from: an aluminium and silicon containing particle also with some iron $(A)$, and a silicon containing particle without aluminium also with some magnesium $(B)$. The copper peaks are from the grid, osmium and uranium from the fixative and stain, and potassium and chlorine from the tissue and resin. Thus these peaks were shown to be background by analysing away from such particles $(C)$. A typical spectrum from a titanium containing particle is also shown (D).

including being added to food as binders, desiccants, and anti-caking agents. Certain types have well defined toxicities: crystalline silica, or quartz, ${ }^{13} 14$ is the best described pathological constituent of pneumoconiotic dusts and is a carcinogen. The asbestiform group and erionite are all fibrous silicates that cause chronic lung inflammation, and lung and pleural tumours. The aluminosilicate kaolinite (identified in our study) is a clay mineral and exposure is associated with the pneumoconiosis, kaolinosis. ${ }^{14}$ The other minerals identified in our study have not yet been associated with disease, but their chemical behaviour has potentially important implications in biological systems. ${ }^{15}$ Factors that are important in mineral toxicity include:

- Shape - fibrous minerals are not completely phagocytosed, causing persistent extra cellular deposition of products of activated macrophages; ${ }^{16}$

- Rate of particle dissolution in vivo - asbestos and quartz, for instance, are stable, whereas illite becomes amorphous over time; ${ }^{17}$
- Crystalline structure - different polymorphs have different biological behaviour, exemplified by silica $\left(\mathrm{SiO}_{2}\right)$, where toxicity varies with crystallinity, ${ }^{18}$ while amorphous silica is nontoxic;

- Particle size - with non-fibrous minerals decreasing size is associated with greater toxicity for silica ${ }^{19}$ and titanium dioxide; ${ }^{9}$

- Microtopographies - these vary according to manufacturing techniques and modify toxicity; ${ }^{1012}$

- Surface interaction with other elements and molecules - iron on a mineral surface can act as a Fenton catalyst generating the highly reactive hydroxyl radical from hydrogen peroxide; ${ }^{20}$

- Interaction with micro-organisms - infection with Mycobacterium tuberculosis is facilitated by silica. ${ }^{21}$

The intestine is a selective barrier to macromolecules. The primary route for their transport from the lumen is via specialist membranous epithelial (M) cells, ${ }^{22}{ }^{23}$ which overlie GALT. This allows the interaction of immunocompetent cells with absorbed intact antigen. Inert particles, such as latex beads, are rapidly absorbed via $M$ cells, ${ }^{24}$ the rate depending on their size, and are subsequently passed to GALT macrophages, which may transport them to draining lymph nodes. ${ }^{25} 26$ Submicron sized inorganic microparticles are similarly absorbed, as shown for hydroxyapatite. $^{27}$

There is no evidence from our work that this exogenous intestinal inorganic pigment has a role in the aetiology of human gastrointestinal disease, and indeed its presence in all GALT from uninvolved intestine may argue against this. In podoconiosis, ${ }^{28}$ however, heterogeneous inorganic microparticles derived from soil accumulate in the macrophages of lymphatics draining the lower limbs and cause a destructive lymphangitis resulting in non-filarial elephantiasis of the lower limb. This disease has a precise epidemiology, for it occurs only in areas with soils derived from neo-volcanic rock and in the barefoot agrarian population. Microanalysis of these particles shows considerable similarities in size (submicron) and particle type (kaolinite and other silicates plus titania polymorphs) to those in the pigment of intestinal cells. In podoconiosis, the response to particles is idiosyncratic, with identical accumulations of particulates in the lymphatics of all the exposed population, but the disease occurs in only a small minority. It has also been proposed that the immunomodulatory effect of the particles is responsible for the endemic Kaposi's sarcoma found in these areas. ${ }^{29}$

The concept that inorganic particulates in the diet can produce Crohn's disease is not new. Dogs fed particulate silica were proposed as an early model for the disease, ${ }^{30}$ while more recently toothpaste, which contains high levels of abrasive and whitening inorganic particles, has been implicated. ${ }^{31}$ The principal aim of this study was to characterise fully the physicochemical nature and source of the inorganic pigment in human GALT and not to determine its potential for pathogenicity. However, 


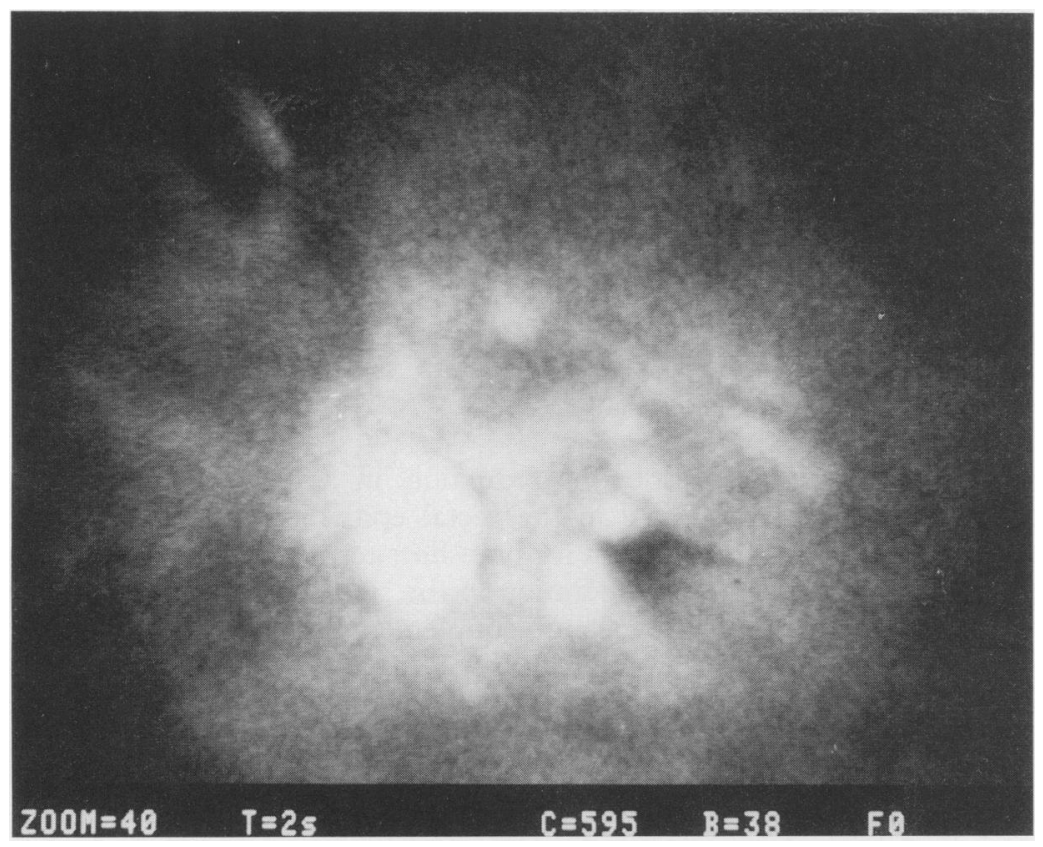

Figure 7: Imaging electron energy loss spectroscopy selects electrons of an elementally specific energy; therefore areas of high elemental concentration relative to the surroundings can be detected and are indicated with a brighter image. This figure (original $\times 100000$ ) shows the oxygen rich content of some intra-vesicular microparticles (white) compared to the surrounding tissue background (grey/black). No other anionic elements were detected in any microparticles.
Trustees of St Thomas' Hospital. We thank Professor J A Catt for help with identification of aluminosilicates.

1 Urbanski SJ, Arsenault AL, Green FHY, Haber G. Pigment resembling atmospheric dust in Pever's patches. Mod Pathol 1989; 2: 222-6.

2 Shepherd NA, Crocker PR, Smith AP, Levison DA. Exogenous pigment in Peyer's patches. Hum Pathol 1987; 18: $50-4$

3 Ghadially FN, Boone SA, Walley VM. A comparison of the ultrastructure of pigment granules in melanosis ilei and pulmonary lymph nodes. Histopathology 1993; 23: 167-72

4 Powell JJ. Aluminium in the gastrointestinal tract. Iondon: University of London, 1994: 101-8. PhD dissertation.

5 Heaney PJ, Banfield JA. Structure and chemistry of silica, metal oxides, and phosphates. In: Guthrie GD, Mossman BT, eds. Health effects of mineral dusts. Washington: Mineralogical Society of America, 1993.

6 Barksdale J. Titanium - its occurrence, chemistry and technology. New York: Ronald, 1966.

7 Lee KP, Trochimowicz HJ, Reinhardt CF. Pulmonary response of rats exposed to titanium dioxide by inhalation for two years. Toxicol Appl Pharmacol 1985; 79: 179-82.

8 Chen JL, Fayerweather WE. Epidemiologic study of workers exposed to titanium dioxide. F Occup Med 1988; 30: 937-42.

9 Driscoll KE, Maurer JK. Cytokine and growth factor release by alveolar macrophages: potential biomarkers of pulmonary toxicity. Toxicol Pathol 1991; 19: 398-405.

10 Nolan RP, Langer AM, Weisman I, Herson GB. Surface character and membranolytic activity of rutile and anatase: two titanium dioxide polymorphs. Br f Ind Med 1987; 44: 687-98.

11 Cai R, Kubota Y, Shuin T, Sakai H, Hashimoto K, Fujishima A. Induction of cytotoxicity by photoexcited $\mathrm{TiO}$, particles. Cancer Res 1992; 52: 2346-8.

12 Hedenborg $M$. Titanium dioxide induced chemiluminescence of human polymorphonuclear leukocytes. Int Arch Occup Environ Health 1988; 61: 1-6.

13 Seaton A. Pneumoconiosis. In: Weatherall DJ, Ledingham JGG, Warrell DA, eds. Oxford textbook of medicine. Oxford: Oxford University Press, 1987.

14 Ross M, Nolan PN, Langer AM, Cooper WC. Health effects of mineral dusts other than asbestos. In: Guthrie ??, Washington: Mineralogical Society of America, 1993.

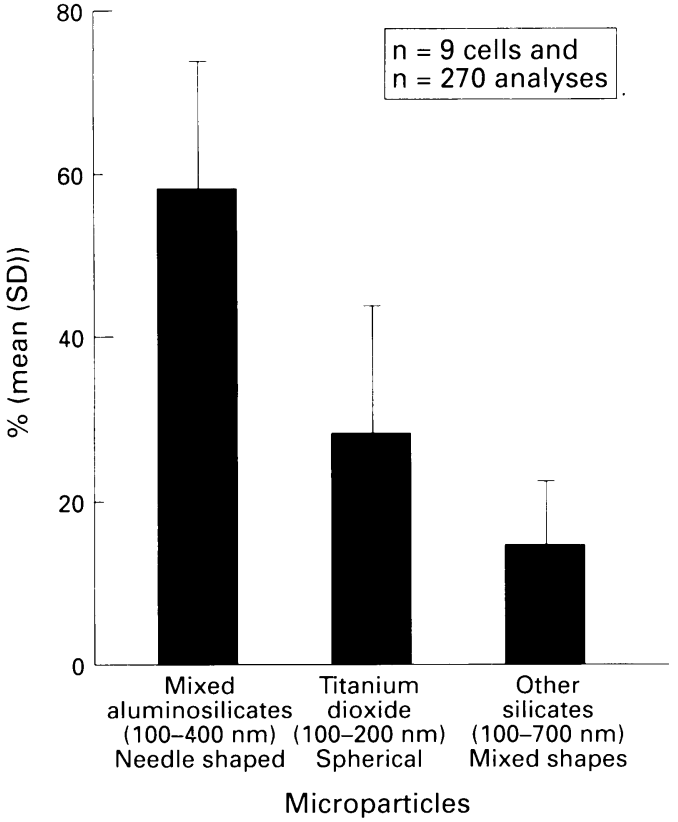

Figure 8: Distribution and shape of intravesicular microparticles greater than $100 \mathrm{~nm}$ in length. Ranges represent largest and smallest particles measured for each type. All particles less than $100 \mathrm{~nm}$ were aluminosilicates, but are not shown in the above analyses.

the assumption that these particulates are inert may not be correct and we are carrying out further work on the pharmacokinetics and dynamics of these dietary inorganic particles in health and disease.

This work was helped by Carl-Zeiss Ltd and English China Clays International and supported by the Crohn's in Childhood Research Association, the National Association for Colitis and Crohn's Disease, the Jean Shanks Foundation, and the Special

5 Laszlo P Chemical reactions on clays. Science 1987; 235: 1473-77.

16 Goodlick LA, Kane AB. The role of reactive oxidant metabolites in crocidolite toxicity to macrophages. Cancer Res 1986; 46: 5558-66.

7 Berry JP, Henoc P, Galle P. Transformation of crystalline particles. Am F Pathol 1978; 93: 27-35.

18 Wiessner JH, Henderson JJ, Sohnle PG, Mandel NS, Mandel GS. The effect of crystal structure on mouse lung inflammation and fibrosis. Am Rev Respir Dis 1988; 138: 445-50.

19 Tebbens BD, Schulz RZ, Drinker P. The potency of silica particles of different size. F Indus Hygienc Toxicol 1945; 27 $199-200$.

20 Kennedy TP, Dodson R, Rao NV, Baser M, Tolley E, Hoidal JR. Dusts causing pneumoconiosis generate $\mathrm{OH}$ and produce hacmolysis by acting as Fenton catalysts. Arch Biochem Biophys 1989; 269: 359-64.

21 Allison AC, D'Arcy Hart P. Potentiation by silica of the growth of Mycobacterium Tuberculosis in macrophage cultures. British Foumal of Experimental Pathology 1968; 49: 465-76.

22 Wolf JL, Bye WA. The membranous epithelial (M) cell and the mucosal immune system. Ann Rev Med 1984; 35: 95-112.

23 Sanderson IR, Allan Walker W. Uptake and transport of macromolecules by the intestine: Possible role in clinical disorders. Gastroenterology 1993; 104: 622-39.

24 Sass MD, Dreyer HP, Seifert J. Rapid insorption of small particles in the gut. Am $\mathcal{F}$ Gastroenterol 1990; 85: 255-60.

25 LeFevre ME, Olivo R, Vanderhoff JW, Joel DD Accumulation of latex in Peyer's patches and its subsequent appearance in villi and mesenteric lymph nodes. Proc Soc Exp Biol Med 1978; 159: 298-302

26 Wells CL, Maddaus MA, Erlandsden SL, Simmons RL. Evidence for the phagocytic transport of intestinal particles in dogs and rats. Infect Immun 1988; 56: 278-82.

27 Amerongen $\mathrm{MH}$, Michetti P, Weltzin RW, Lee TH, Krachenbuhl JP, Neutra MR. Transepithelial delivery of a recombinant HIV protein on hydroxyappatite for producrecom of monoclonal anti-gp 120 IgA antibodies. $f$ Cod Biol tion of monoclonal anti-gp 120 IgA antibodies. $f$ Cell Biol
1991; 115: 237a.

28 Price EW. Podoconiosis, non-filarial clephantiasis. Oxford: Oxford University Press, 1990.

29 Ziegler JL. Endemic Kaposi's sarcoma in Africa and local volcanic soils. Lancet 1993; 342: 1348-51.

30 Chess S, Chess D, Olander G, Benner W, Cole WH Production of chronic enteritis and other systemic lesions by ingestion of finely divided foreign materials. Surgery 1950;27: 221-34

31 Sullivan SN. Hypothesis revisited: toothpaste and the cause of Crohn's disease. Lancet 1990; 336: 1096-7. 